\title{
Molecular Dynamics and Mechanical Properties Correlations of PA6/PPO Blends Compatibilized with SMA
}

\author{
PETER P. CHU, ${ }^{1}$ JIEH-MING HUANG, ${ }^{2,3}$ HEW-DER WU, ${ }^{1}$ CHIH-RONG CHIANG, ${ }^{2}$ FENG-CHIH CHANG $^{2}$ \\ ${ }^{1}$ Department of Chemistry, National Central University, Chung-Li, Taiwan 32054, Republic of China \\ ${ }^{2}$ Institute of Applied Chemistry, National Chiao-Tung University, Hsinchu, Taiwan 30034, Republic of China \\ ${ }^{3}$ Van Nung Institute of Technology, Chung-Li, Taiwan 32054, Republic of China
}

Received 17 August 1998; revised 7 December 1998; accepted 8 December 1998

\begin{abstract}
The effects of the compatibilizer, styrene maleic anhydride (SMA-8\% MA) upon the change of morphology and molecular dynamics of polyamide-6 (PA6) and poly (2,6-dimethyl-1,4-phenylene oxide) (PPO) blends were investigated by means of solidstate NMR techniques. With increasing amounts of SMA, the domains correspond to PA6 and PPO are reduced and the polymer segmental mobility increased. The correlation between NMR relaxation time, $T_{1 \rho}^{H}$, and the bulk mechanical properties provide a molecular level understanding of the modification of molecular dynamics by the compatibilizer (SMA). The correlation shows that the tensile strength is governed mainly by the morphology, but modulated by the PA6 crystallinity, while the tensile elongation and impact strength are closely affected by both the molecular mobility and morphology. The annealing process improved only the tensile strength, but deteriorated tensile elongation and impact strength due to the increase of PA6 crystallinity, which induced phase separation after annealing. This study raised an important point that the polymer mechanical properties are most sensitive to the molecular structure and dynamics take place within the range of $20 \AA$ to few hundred $\AA$. @ 1999 John Wiley \& Sons, Inc. J Polym Sci B: Polym Phys 37: 1155-1163, 1999
\end{abstract}

Keywords: polyamide-6; poly(phenylene oxide); polymer blend; mechanical properties; $T_{1 \rho}^{H} ;$ solid-state NMR

\section{INTRODUCTION}

It has been speculated that the type of motion most influential to polymer properties is probably the chain liberation which occurring in the range from $20 \AA$ to few hundred $\AA$ scale. ${ }^{1}$ High-resolution solid-state NMR spectroscopy has repeatedly proven to be effective for investigating molecular dynamics and for characterizing molecular structures of polymers. ${ }^{2-4}$ In particular, proton spin lattice relaxation time in the rotating frame $\left(T_{1 \rho}^{H}\right)$

Correspondence to: P. P. Chu

Journal of Polymer Science: Part B: Polymer Physics, Vol. 37, 1155-1163 (1999) ๑) 1999 John Wiley \& Sons, Inc.

CCC 0887-6266/99/111155-09 and transverse relaxation time $\left(T_{2}\right)$ were frequently used to provide miscibility and molecular structural information for polymer blends. ${ }^{5-7}$ Proton relaxation parameters closely monitor the molecular dynamics. Therefore, they are used to study the relationships between molecular motion and mechanical properties. Since $T_{1 \rho}^{H}$ and relaxation time in the laboratory frame $\left(T_{1}^{H}\right)$ are influenced to different degree by the spin-diffusion effects, these measurements are usually used to differentiate domains with minimum path lengths of ca. $20 \AA\left(T_{1 \rho}^{H}\right)$ and ca. $200 \AA\left(T_{1}^{H}\right)$. The main focus of this study is to understand the effects of molecular dynamic upon polymer mechanical properties. The objective is achieved 
through the correlation between proton relaxation time (a microscopic property) and polymer properties (macroscopic properties). In so doing, the effects of polymer segmental motion occurring in the $20 \AA$ to few hundred $\AA$ scale on the bulk mechanical properties can be illustrated.

The system chosen for this study is the polyamide-6 (PA6) and poly(2,6-dimethyl-1,4-phenylene oxide) (PPO) blends coupled with the compatibilizer, styrene maleic anhydride (SMA). Blending of both polymers could produce novel materials with properties compensating the deficiencies of each other. This idea has attracted great interest from both the industry and academics. Numerous papers have subsequently reported using copolymers as compatibilizer to blend with both PA and PPO. ${ }^{8-14}$ Recently, we have shown the SMA compatibilizer greatly improved the PA6/PPO blend compatibility and substantially improved the mechanical properties. ${ }^{15}$ Although the morphology and mechanical properties appears to be closely related, the relationships between the bulk properties and microstructure remain ambiguous. Furthermore, the annealing process, which produced diverse effects to different mechanical properties, is another issue to be resolved.

In this report, the functions of compatibilizer between PA6 and PPO are thoroughly illustrated, and molecular motion information systematically studied by solid-state NMR. The interplay between the molecular motion, structure, morphology, and their effects upon bulk properties modified by the compatibilizer will be examined.

\section{EXPERIMENTAL}

The PA6 used in this study is a commercial product, Novamid 1010C2, produced by Mitsubishi Kasei Co. Ltd. of Japan. The SMA (styrene maleic anhydride) copolymer containing 8 wt \% maleic anhydride, Dylark 232, was obtained from Arco Co. PPO powder was purchased from General Electric Co. and has a normal intrinsic viscosity of $0.4 \mathrm{dl} / \mathrm{g}$ measured in chloroform at $25^{\circ} \mathrm{C}$.

All PA6/PPO blends were prepared on a corotating $30 \mathrm{~mm}$ twin-screw extruder $(\mathrm{L} / \mathrm{D}=36$, Sino-Alloy Machinery Inc.) with a rotational speed of $280 \mathrm{rpm}$. Vacuum was applied in the decompression zone. The barrel temperatures were set from 210 to $290^{\circ} \mathrm{C}$. The testing specimens were prepared by an Arburg 3 oz injection molding machine for standard ASTM specifica- tion. The temperatures of injection molding were adjusted to optimize the processing conditions, depending on the compositions.

The morphologies of the injection molded specimens were examined using a Hitachi S-570 scanning electron microscope (SEM) at an accelerating voltage of $20 \mathrm{kV}$. Cryogenically fractured surfaces of the moulded specimens were coated with a thin film of gold prior to SEM examination.

Tensile tests were conducted under ambient conditions using an Instron Universal Testing machine Model 4201 according to ASTM-D638. The cross-head speed was $5 \mathrm{~mm} / \mathrm{min}$. Unnotched Izod impact test was carried out under ambient conditions according to ASTM-D256. After injection molding and prior to test, specimens were conditioned in the laboratory atmosphere for at least 7 days. Annealing was carried out at $200^{\circ} \mathrm{C}$ for $0.5-2.0 \mathrm{~h}$ in a temperature controlled oven.

High-resolution solid-state ${ }^{13} \mathrm{C}$ NMR experiments were carried out on a Bruker DSX-300 spectrometer operated at resonance frequencies of 300.13 and $75.475 \mathrm{MHz}$ for ${ }^{1} \mathrm{H}$ and ${ }^{13} \mathrm{C}$, respectively. ${ }^{13} \mathrm{C}$ CP/MAS NMR spectra were measured with $3.9 \mu \mathrm{s} 90^{\circ}$ pulse width, $3 \mathrm{~s}$ pulse delay time, $30 \mathrm{~ms}$ acquisition time, and with 1024 scans. All NMR spectra were recorded with broad band proton decoupling $\left(\nu_{1}=64 \mathrm{kHz}\right)$, and normal crosspolarization pulse sequence. The magic angle sample spinning (MAS) rate of $4 \mathrm{kHz}$ was used to avoid overlapping resonance lines. Proton spinlattice relaxation times in the rotating frame $\left(T_{1 \rho}^{H}\right)$ were measured indirectly via carbon observation using a $90^{\circ}$ - $\tau$-spin lock pulse sequence prior to cross-polarization. Data acquisitions were performed with ${ }^{1} \mathrm{H}$ decoupling $\left(\nu_{1}=64 \mathrm{kHz}\right)$, using delay times $(\tau)$ ranging from 0.2 to $12 \mathrm{~ms}$. Without further specification, the typical contact time of $1.5 \mathrm{~ms}$ was used.

\section{RESULTS AND DISCUSSION}

The PA6/PPO $=30 / 70$ blend is selected for present study of the effects of microscopic dynamics upon bulk mechanical properties since it exhibits the most pronounced property improvement with SMA. ${ }^{15}$ The cause-effect relationship served as a reference for other blend compositions.

\section{Morphologies}

SEM photomicrograph is used to monitor the improvement of morphology with compatibilizer. 


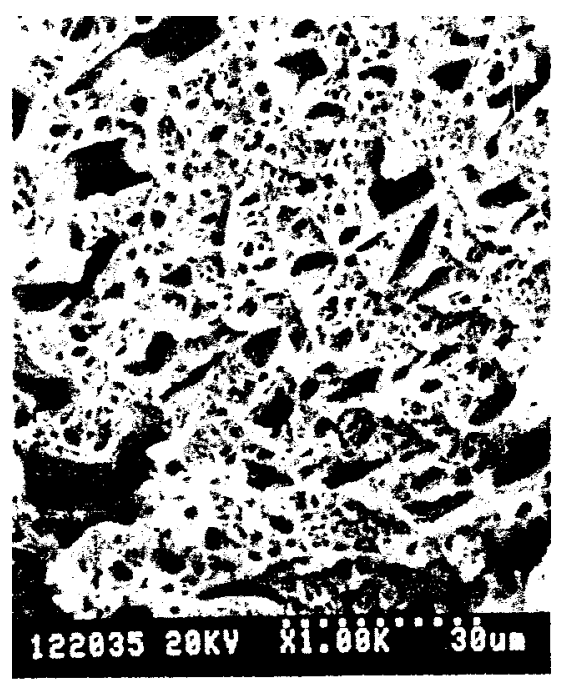

(a) $\mathrm{PA} 6 / \mathrm{PPO}=30 / 70$

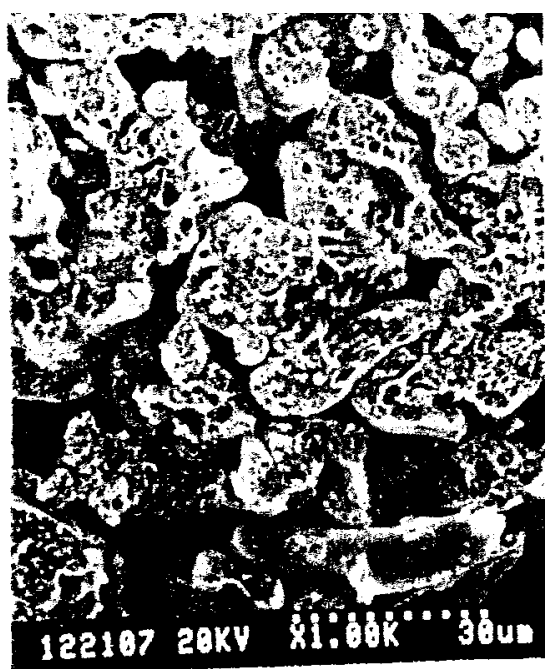

(b) $\mathrm{PA} 6 / \mathrm{PPO} / \mathrm{SMA}=30 / 70 / 1$

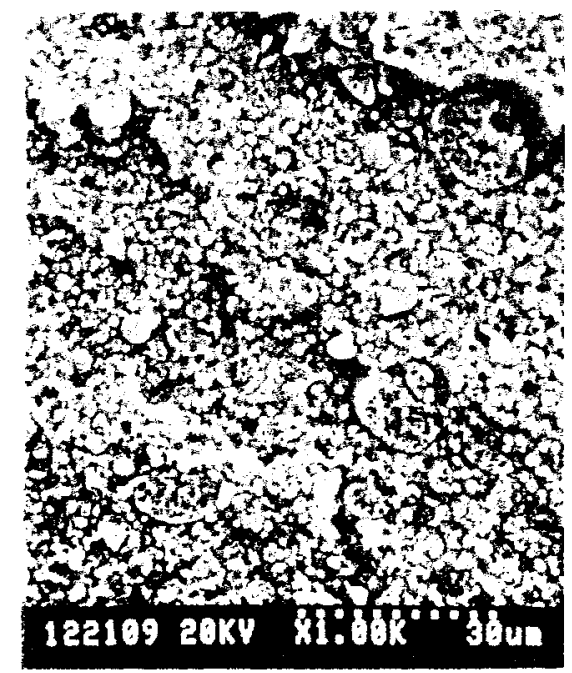

(c) $\mathrm{PA} 6 / \mathrm{PPO} / \mathrm{SMA}=30 / 70 / 2$

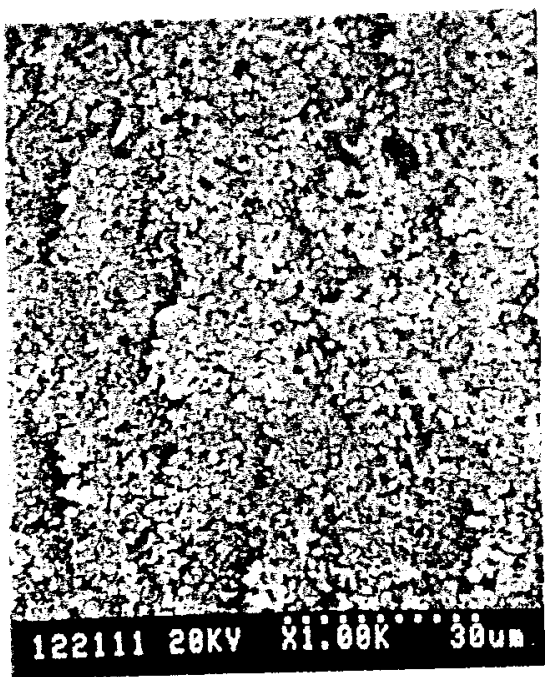

(d) $\mathrm{PA} 6 / \mathrm{PPO} / \mathrm{SMA}=30 / 70 / 10$

Figure 1. Etched SEM micrographs of the PA6/PPO blends. (a) PA6/PPO $30: 70$, (b) PA6/PPO/SMA 30 : 70 : 1, (c) PA6/PPO/SMA $30: 70:$, (d) PA6/PPO/SMA $30: 70: 10$.

Figure 1 illustrates the micrographs of the PA6/ PPO $=30 / 70$ blends with various compatibilizer (SMA) contents. The miscibility improvement in submicron scale clearly shows that the domain size of the compatibilized PA6/PPO blend is reduced with increasing SMA content. A compatibilized blend, in general, has finer phase domain, greater interfacial contact area, and higher interfacial adhesion compared with the corresponding uncompatibilized blend. As observed in Figure 1(a), the uncompatibilized PA6/PPO blend shows a co-continuous phase structure, even though the PA6 is the minor component in the blend. Figure 1(b) shows that the blend containing $1.0 \mathrm{phr}$ SMA also possesses a nearly co-continuous morphology, however, PPO is better dispersed within PA6 domain. The reduction of size of the PA6-included PPO particles after compatibilization is apparent. 
The most drastic morphology change is around $2.0 \mathrm{phr}$ SMA [comparing Fig. 1(b) and 1(c)]. The PPO domains have virtually coalesced and the PPO exists as very fine particles well dispersed within the PA6 phase. It is interesting to note that PA6 has shifted from a co-continuous phase into a continuous matrix as the quantity of SMA increases. By adding $10 \mathrm{phr}$ SMA, the morphology of the blend is extremely fine and the fine PPO particles are evenly distributed [Fig. 1(d)]. It is expected that the in situ-formed SMA-g-PA6 copolymer molecules anchoring on the interface is responsible for such improvement. The SMA and PA6 segments in the SMA-g-PA6 copolymer at the interface mixed intimately with PPO and PA6 phases. Greater quantity of SMA therefore tends to form greater numbers of the SMA-g-PA6 copolymers, which improves the compatibility between PA6 and PPO.

Furthermore, the mechanical properties are also found to be improved with the enhanced miscibility induced by the compatibilizer. ${ }^{15}$ At the first approximation, it appears that the finer morphology is responsible for the improvement of mechanical properties. However, strong evidence by solid-state NMR measurements indicate that structural characteristics such as degree of crystallinity and molecular segmental motion are also responsible for improving different mechanical properties.

\section{${ }^{13} \mathrm{C}$ CP/MAS NMR Spectra}

${ }^{13} \mathrm{C}$ CP/MAS NMR spectra of PA6, PPO, and the PA6/PPO/SMA (30/70/10) blend are shown in Figure 2. The assignments were made based upon solution NMR spectra and were consistent with previous reports. ${ }^{16,17}$ The ${ }^{13} \mathrm{C}$ signals of the methylene $\left(\mathrm{C}_{1} \sim \mathrm{C}_{5}\right)$ groups; carbonyl group of PA6 $\left(\mathrm{C}_{6}\right)$; methyl of PPO (16.4 ppm); the aromatic carbons of PPO (100 $160 \mathrm{ppm})$; and the benzene ring of SMA (127.8 ppm) were well resolved, allowing for clear estimations of $T_{1 \rho}^{H}$, and the peak width of the respective moieties in the blends. SMA signals are either hidden under the spinning side band or too weak to be detected.

Under strong proton decoupling condition, the MAS residual line width, inversely proportional to ${ }^{1} \mathrm{H} T_{2}$ relaxation time, is sensitive to low-frequency motions (few $\mathrm{kHz}$ ) originated from the anisotropic reorientation motion of polymers. The peak widths thus provide information related to the effects of intramolecular couplings, chemical crosslinking, and chain entanglement on the mo-

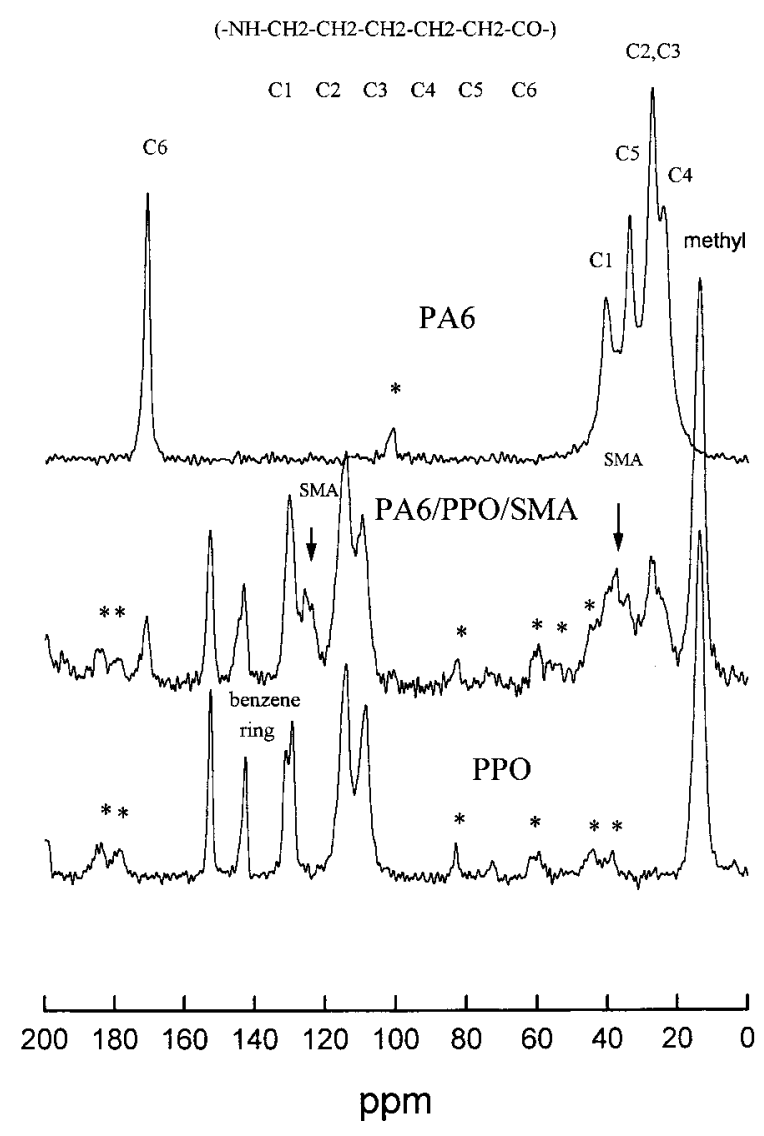

Figure 2. ${ }^{13} \mathrm{C}$ CP/MAS NMR spectra of PA6 (top), PA6/PPO/SMA (30: $70: 10$ ) (middle), and PPO (bottom). Asterisks denote spinning sidebands.

lecular levels. When PA6/PPO blend is compatibilized with SMA, the resonance width of methylene group $\left(\mathrm{C}_{1} \sim \mathrm{C}_{5}\right)$ appears wider than its neat polymer under proton decoupling. All the peak widths of PPO are also increased in PA6/PPO blend with SMA compatibilizer. The line width may be caused by the proximity of the motional correlation time with the inverse of the MAS spinning rate. Prior study ${ }^{7}$ suggests that MAS residual line width increase when motional frequency occurs in the same order as sample rotation frequency. However, we have not observed appreciable changes in line width with changing rotational frequency. Therefore, the motional behavior with correlation time in the order of $10^{-2}$ $\sim 10^{-4} \mathrm{sec}$, is not likely the source of the broadening. In addition, change proton decouping field from $64 \mathrm{kHz}$ to $50 \mathrm{kHz}$ does not produce appreciable change in line width, ruling out the broadening being due to insufficiency of decoupling strength. It is evident that the broadening is originated from the inhomogeneity of structure caus- 


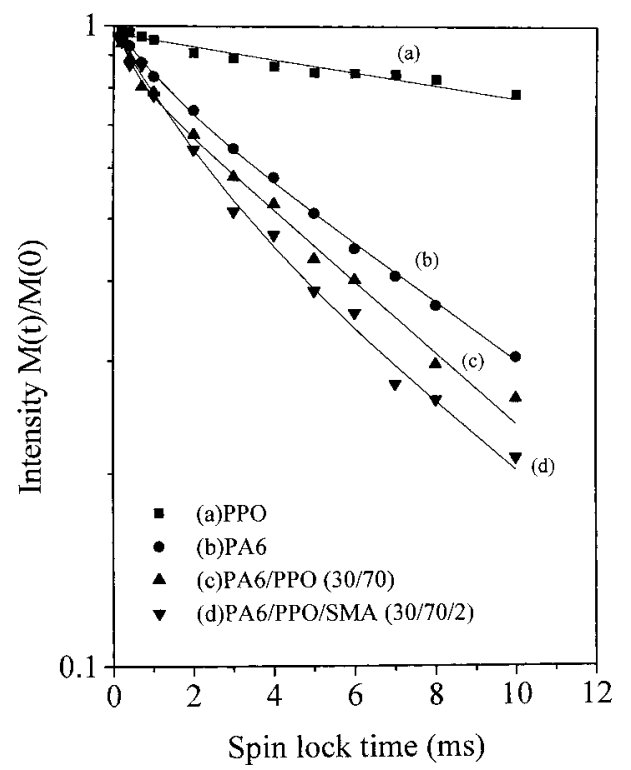

Figure 3. Logarithmic plots of the magnetization intensities versus proton spin-lock time for PA6, PPO, and PA6/PPO blends at contact time of $1.5 \mathrm{~ms}$. (a) PPO (ם), (b) PA6 (-), (c) PA6/PPO $30: 70$ (山), (d) PA6/PPO/ SMA $30: 70: 2(\boldsymbol{\nabla})$. The solid line is the best fit to the experimental data based on Eq. (1).

ing by the addition of SMA. The structural inhomogeneity gives rise to a distribution of chemical shift from their parent polymers, leading to the NMR absorption lines broadening.

\section{$T_{1 \rho}^{H}$ Relaxation Times}

$T_{1 \rho}^{H}$ relaxation time reveals the inhomogeneity of the domains. A proton $T_{1 \rho}^{H}$ via resolved carbon resonance provides a convenient access to the complicated class of polymer blends. $T_{1 \rho}^{H}$ can be observed for protons located in different morpho- logical domains. The spin diffusion is weak and can be neglected provide that the coupled domain is large enough. The normalized ${ }^{1} \mathrm{H}$ magnetization $M(\tau)$ of PA6 is simulated by double-exponential function which reflects the two relaxation rates of both domains as follow:

$$
\begin{aligned}
M(\tau) / M(0)=x_{a} \exp \left(-\tau / T_{1 \rho, S}^{H}\right) & \\
& +x_{c} \exp \left(-\tau / T_{1 \rho, L}^{H}\right)
\end{aligned}
$$

where $T_{1 \rho, S}^{H}$ and $T_{1 \rho, L}^{H}$ correspond to the relaxation times in the short and long components, while $x_{a}$ and $x_{c}$ are the respective weight fractions of the domain. The magnetization decay curves of the ${ }^{13} \mathrm{C}$ signal for $\mathrm{C}_{2}$ and $\mathrm{C}_{3}(30 \mathrm{ppm})$ are plotted on a logarithmic scale vs. proton spin-lock time in Figure 3 for PA6, PA6/PPO (30/70) and PA6/PPO/SMA (30/70/2). Shown in Figure 3(a) is the relaxation curve of PPO for comparison. Biexponential decays are apparent for both blends and the parent PA6 samples. In fact, blends with higher SMA content also showed bi-exponential nature. The two components are assigned to the relaxation from PA6 protons located in the mobile (short time component, mainly from the amorphous) and the rigid (long time component, mainly from the crystalline) regions. Obviously, the domains in these blends are all larger than 20 $\AA$, and the spin diffusion is insufficient to average the relaxation into a single component, even for the higher SMA content. The $T_{1 \rho}^{H}$ values and the corresponding weight fractions deduced from this procedure are summarized in the second and the third columns in Table I for the $30 \mathrm{ppm}$ peak with different amounts of SMA compatibilizer. It is clear that the crystalline fraction decrease as the SMA compatibilizer content increase. The de-

Table I. $\quad T_{1 \rho}^{H}$ Values of $30 \mathrm{ppm}$ and the Mechanical Properties of PA6/PPO Blends with Various Compatibilizer (SMA) Content

\begin{tabular}{ccccccc}
\hline & \multicolumn{2}{c}{$T_{1 \rho}^{H}(\mathrm{~ms})$ of $30 \mathrm{ppm}$} & & \multicolumn{2}{c}{ Mechanical Properties } \\
\cline { 2 - 3 } $\begin{array}{c}\text { Composition of } \\
\text { PA6/PPO/SMA }\end{array}$ & $\begin{array}{c}\text { Short Time } \\
\text { Component }\end{array}$ & $\begin{array}{c}\text { Long Time } \\
\text { Component }\end{array}$ & $\begin{array}{c}\text { Tensile Strength } \\
(\text { Mpa })\end{array}$ & $\begin{array}{c}\text { Tensile Elongation } \\
(\%)\end{array}$ & $\begin{array}{c}\text { Unnotched Izod } \\
\text { Impact (J/M) }\end{array}$ \\
\hline 30/70/0 & $0.42(15 \%)^{\mathrm{a}}$ & $7.79(85 \%)$ & & 28.2 & 2.5 & 111.3 \\
$30 / 70 / 1$ & $0.98(19 \%)$ & $8.41(81 \%)$ & & 39.4 & 3.2 & 132.3 \\
$30 / 70 / 2$ & $2.21(37 \%)$ & $8.76(63 \%)$ & & 47.0 & 3.9 & 145.3 \\
$30 / 70 / 5$ & $2.44(40 \%)$ & $9.12(60 \%)$ & & 52.9 & 4.2 & 328.1 \\
$30 / 70 / 10$ & $4.10(45 \%)$ & $9.39(55 \%)$ & 61.5 & 6.7 & 461.0 \\
\hline
\end{tabular}

a The value in parenthesis represents the weight fraction of the respective component. 
Table II. $\quad T_{1 \rho}^{H}$ Values of PPO (16.4 ppm) with Various Compatibilizer (SMA) Content

\begin{tabular}{cc}
\hline Composition of PA6/PPO/SMA & $T_{1 \rho}^{H}(\mathrm{~ms})$ \\
\hline $30 / 70 / 0$ & 55.1 \\
$30 / 70 / 1$ & 53.2 \\
$30 / 70 / 2$ & 48.1 \\
$30 / 70 / 5$ & 35.4 \\
$30 / 70 / 10$ & 32.4 \\
\hline
\end{tabular}

crease with addition of SMA is understood for the formation of more SMA-g-PA6 segments that leads to the reduction of PA6 crystalline domain. These segments would serve as interfacial compatibilizer between PPO and PA6 to enhance the miscibility.

PPO, on the other hand, shows only a single $T_{1 \rho}^{H}$ relaxation. Summarized in Table II are the $T_{1 \rho}^{H \rho}$ values for PPO in various blends calculated from the methyl resonance at $16.4 \mathrm{ppm}$. The relaxation time is reduced from $55.1 \mathrm{~ms}$ to $32.4 \mathrm{~ms}$ with increasing SMA. The decrease of $T_{1 \rho}^{H}$ in the PPO (amorphous) domain suggests an increase of mobility in PPO with increasing SMA. Note that with increasing SMA, the $T_{1 \rho}^{H}$ in the PA6 short component increases from $0.42 \mathrm{~ms}$ to $4.10 \mathrm{~ms}$ while the long component is less affected which increased slightly from $7.79 \mathrm{~ms}$ to $9.39 \mathrm{~ms}$. These changes are closely related to the improved miscibility. Since PA6 is the minor component, the improved miscibility by SMA homogenized the segmental dynamics which brings the relaxation time of amorphous PA6 and PPO to be closer, thus lengthening the shorter relaxation component of PA6. Since PA6 crystallite is better dispersed in the blend due to presence of SMA, the crystalline PA6 relaxation time is also brought closer to that of PPO, although this effect is less pronounced than the amorphous PA6. $T_{1 \rho}^{H}$ relaxation study shows SMA not only homogenizes the morphology, it also homogenize the mobility for different molecular segments in the polymer bulk.

\section{Effects of Annealing}

The polymer blend processed by a twin-screw extruder exists in a kinetics equilibrium state. However, the annealing process created different effects to different mechanical properties. The mechanical properties are tabulated in the fourth to the sixth columns in Table I (before annealing) and Table III (after annealing). As shown in Table III, only the tensile strength is improved while tensile elongation and Izod impact strength are both deteriorated after annealing. Figure 4 shows the dramatic change of magnetization decay under spin locking of the $30 \mathrm{ppm}$ peak for $\mathrm{PA} / \mathrm{PPO} /$ SMA $=30 / 70 / 10$ blends before and after annealing at $200^{\circ} \mathrm{C}$ for $1 \mathrm{~h}$. The $T_{1 \rho}^{H}$ values and the corresponding fraction derived from bi-exponential decomposition are tabulated in the second and the third columns in Table III. The changes in weight fraction suggest that PA6 crystallinity is increased with annealing. It is of note that the long component originates from the more rigid domains and the fraction cannot be taken directly as the degree of crystallinity.

To further confirm that annealing indeed induces PA6 crystallization, the relaxation behavior with annealing time is examined. Table IV summarizes the change of $T_{1 \rho}^{H}$ values and the crystalline weight fraction as a function of annealing time. As observed from Table IV, the PA6 crystalline fraction is indeed increased with annealing

Table III. $T_{1 \rho}^{H}$ Values of $30 \mathrm{ppm}$ in PA6/PPO/SMA Blends and Its Mechanical Properties after Annealing ${ }^{\mathrm{a}}$

\begin{tabular}{|c|c|c|c|c|c|}
\hline \multirow[b]{2}{*}{$\begin{array}{l}\text { Composition of } \\
\text { PA6/PPO/SMA }\end{array}$} & \multicolumn{2}{|c|}{$T_{1 \rho}^{H}(\mathrm{~ms})$ of $30 \mathrm{ppm}$} & \multicolumn{3}{|c|}{ Mechanical Properties } \\
\hline & $\begin{array}{l}\text { Short Time } \\
\text { Component }\end{array}$ & $\begin{array}{l}\text { Long Time } \\
\text { Component }\end{array}$ & $\begin{array}{c}\text { Tensile Strength } \\
\text { (Mpa) }\end{array}$ & $\begin{array}{c}\text { Tensile Elongation } \\
\qquad(\%)\end{array}$ & $\begin{array}{l}\text { Unnotched Izod } \\
\text { Impact }(\mathrm{J} / \mathrm{M})\end{array}$ \\
\hline $30 / 70 / 0$ & $0.31(11 \%)^{\mathrm{b}}$ & $12.21(87 \%)$ & 26.9 & 2.1 & 75.4 \\
\hline $30 / 70 / 1$ & $0.82(12 \%)$ & $13.12(88 \%)$ & 42.5 & 3.0 & 103.7 \\
\hline $30 / 70 / 2$ & $1.24(12 \%)$ & $14.34(88 \%)$ & 49.4 & 3.3 & 120.3 \\
\hline $30 / 70 / 5$ & $1.78(13 \%)$ & $15.46(87 \%)$ & 54.4 & 3.8 & 288.9 \\
\hline $30 / 70 / 10$ & $2.84(11 \%)$ & $17.80(89 \%)$ & 65.1 & 4.7 & 393.8 \\
\hline
\end{tabular}

a Annealing condition: $200^{\circ} \mathrm{C}$ for $60 \mathrm{~min}$.

$\mathrm{b}$ The value in parenthesis represents the weight fraction of the respective component. 


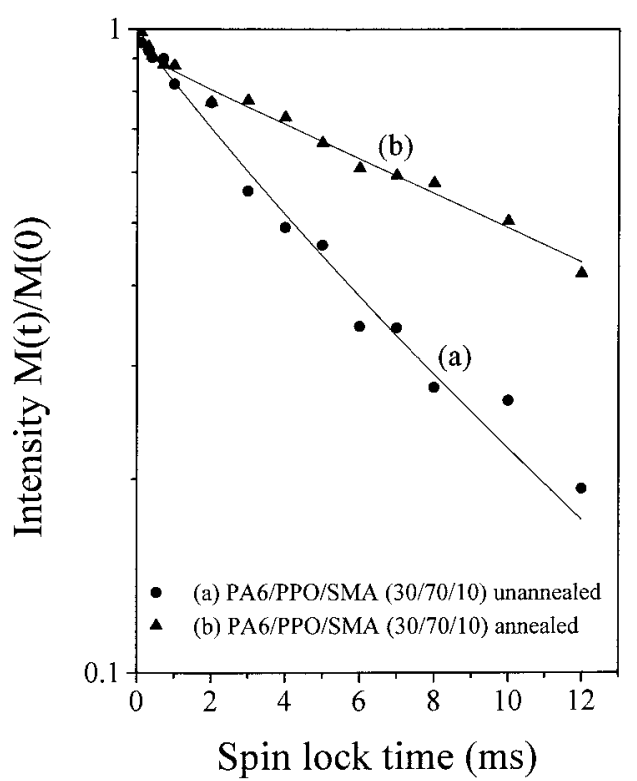

Figure 4. Logarithmic plots of the magnetization intensities of PA6 (C2, C3) versus proton spin-lock time for PA6/PPO/SMA (30:70:10) blends at contact time of $1.5 \mathrm{~ms}$. (a) unannealed (O), (b) annealed at $200^{\circ} \mathrm{C}$ for 60 minutes $(\mathbf{\Delta})$. The solid line is the best fit to the experimental data based on Eq. (1).

time. Concurrently, the long relaxation fraction increases. These results are consistent with the previous studies of semicrystalline polymers, where the relaxation time in the crystalline component increases with increasing crystallinity. ${ }^{18}$ With more severe phase separation due to the increase of PA6 crystalline domain, the relaxation time of the long time component increases. The result proves unequivocally that the annealing process has increased PA6 crystallinity. This microstructure change, too small to be resolved by

Table IV. $T_{1 \rho}^{H}$ Values of $30 \mathrm{ppm}$ in PA6/PPO/SMA (30/70/10) Blends under Various Annealing Time ${ }^{a}$

\begin{tabular}{clc}
\hline & \multicolumn{2}{c}{$T_{1 \rho}^{H}(\mathrm{~ms})$ of $30 \mathrm{ppm}$} \\
\cline { 2 - 3 } $\begin{array}{c}\text { Annealing } \\
(\mathrm{h})\end{array}$ & $\begin{array}{l}\text { Short Time } \\
\text { Component }\end{array}$ & $\begin{array}{l}\text { Long Time } \\
\text { Component }\end{array}$ \\
\hline None & $4.10(45 \%)$ & $9.39(55 \%)$ \\
0.5 & $3.26(20 \%)$ & $10.4(80 \%)$ \\
1.0 & $2.84(11 \%)$ & $17.8(89 \%)$ \\
1.5 & $1.14(9 \%)$ & $18.7(91 \%)$ \\
2.0 & $0.67(8 \%)$ & $20.2(92 \%)$ \\
\hline
\end{tabular}

${ }^{\text {a }}$ Annealing temperature: $200^{\circ} \mathrm{C}$.

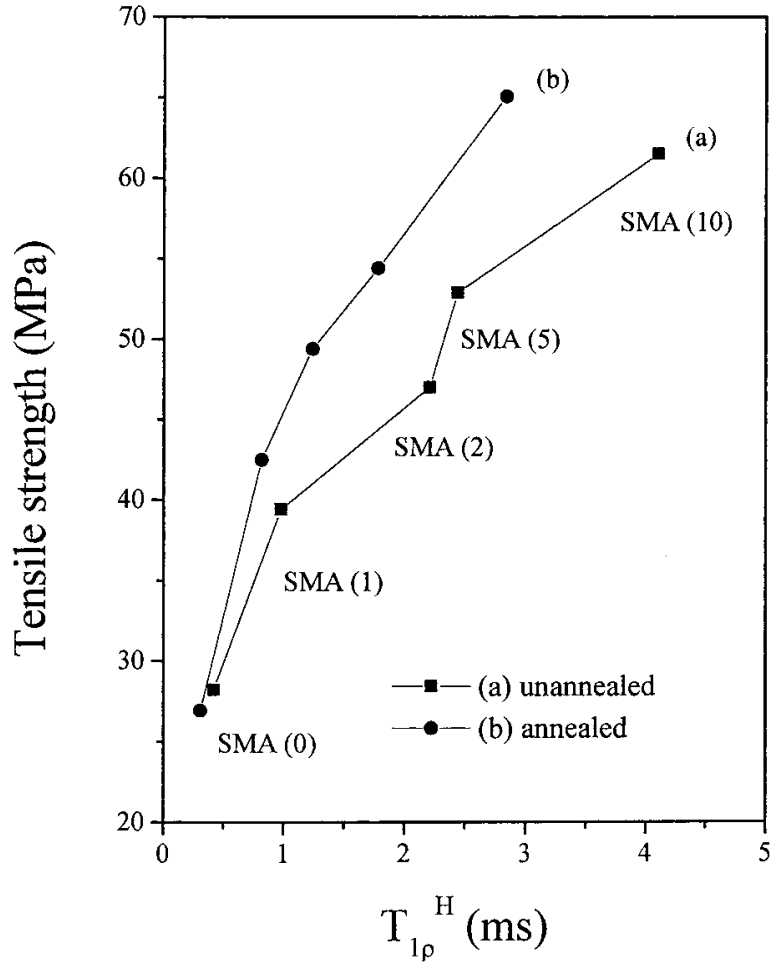

Figure 5. The relationship between the $T_{1 \rho}^{H}$ value and the tensile strength of the PA6/PPO blends. (a) unannealed (匹), (b) annealed at $200^{\circ} \mathrm{C}$ for 60 minutes $(\bullet)$.

SEM, has dramatic effects upon the mechanical properties of the blends as illustrated in the following.

\section{Correlation between Segmental Motion and Bulk Properties}

Correlation between $T_{1 \rho}^{H}$ values with the mechanical properties is the most direct approach to study the cause-effect relationships. As shown in Table I, the tensile strength, tensile elongation and the impact strength are all improved with addition of SMA compatibilizer. As shown in Table III, the improvements are also reproduced in the annealed samples. From $T_{1 \rho}^{H}$ relaxation studies, the molecular segmental motion in the amorphous PA6 and PPO clearly increases with increasing SMA content. The correlation of NMR parameters $\left(T_{1 \rho}^{H}\right.$ of the amorphous PA6) with various mechanical properties are depicted in Figure 5 (with tensile strength), Figure 6 (with tensile elongation), and Figure 7 (with Izod impact strength). As mentioned previously, the longer $T_{1 \rho}^{H}$ of amorphous PA6 suggested higher segmen- 


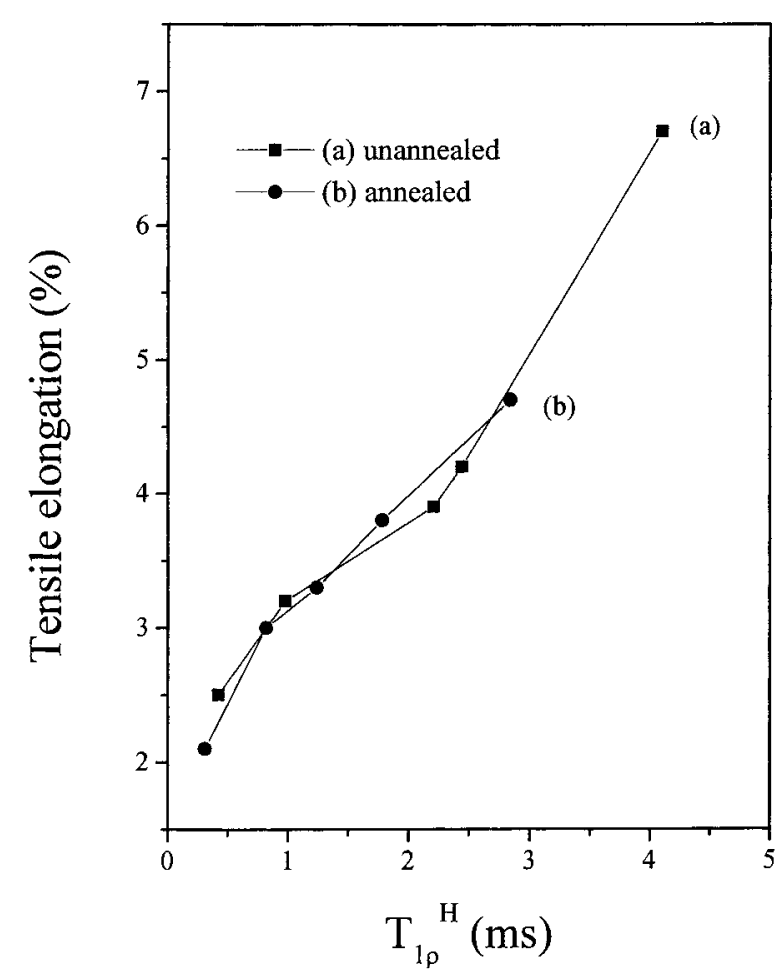

Figure 6. The relationship between the $T_{1 \rho}^{H}$ value and the tensile elongation of the PA6/PPO blends. (a) unannealed (ם), (b) annealed at $200^{\circ} \mathrm{C}$ for 60 minutes (O).

tal mobility in the polymer bulk. The increase of mechanical properties with increasing $T_{1 \rho}^{H}$ (PA6) seems to suggest the segmental mobility in both PPO and PA6 being the major factor contributing to mechanical property. As shown in Figure 5, the correlation between tensile strength and $T_{1 \rho}^{H}$ are separated into two individual curves. The increase in crystallinity by annealing has shifted the relaxation time corresponding to a shorter value. On the other hand, as shown in Figure 6, for samples with and without annealing fall into a single correlation and appears independent of the crystallinity change by annealing. The results suggest that the crystallinity affect the tensile strength but not tensile elongation. The correlation for notched Izod impact strength (Fig. 7) on the annealed and unannealed samples seems to be also separated into two curves as that shown for the tensile strength. A noticeable feature occurred in the sudden increases of impact strength from $2 \mathrm{phr}$ to $5 \mathrm{phr}$ SMA for samples before and after annealing. Recalling that the miscibility improved substantially when the SMA concentration near $2 \mathrm{phr}$, the jump-discontinuity in Izod impact performance suggests the effects of the morphology may outweigh the crystallinity factor.

Certainly, homogeneous morphology is a favorable factor for mechanical property improvement, however other structural characters are also influential to the properties to different degrees. This study concluded that tensile strength is also affected by the degree of crystallinity, the tensile elongation by the molecular mobility in the amorphous domain, and the impact strength is mainly controlled by the miscibility. These observations are consistent with the common understanding ${ }^{19}$ that, (1) higher crystallinity increases the hardness of the material and improves tensile strength, (2) the increase of molecular dynamics and the amount of the amorphous domain favor the elongation, and (3) the finer morphological texture guards against puncture failure during impact. Present NMR studies provide a systematic examination on the effects of these microscopic structural characters upon mechanical properties, as evidenced by the structure-property correlation.

As $T_{1 \rho}^{H}$ is sensitive to change smaller than $\sim 100 \AA$, the good correlation suggests that me-

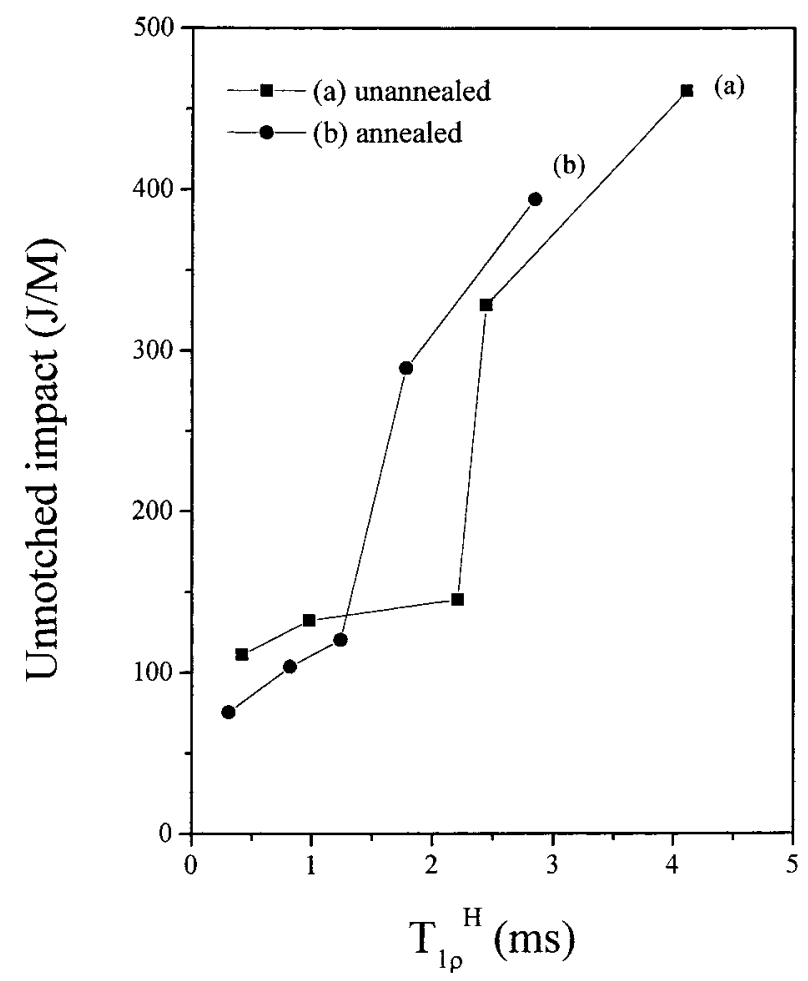

Figure 7. The relationship between the $T_{1 \rho}^{H}$ value and the impact strength of the PA6/PPO blends. (a) unannealed (ם), (b) annealed at $200^{\circ} \mathrm{C}$ for 60 minutes (O). 
chanical properties can be influenced by the structural and motional difference appeared within this small scale.

\section{CONCLUSIONS}

The study examines the effects of molecular dynamics of the PA6/PPO blend and the major factors responsible for the improvement of mechanical properties. The in situ-formed SMA-g-PA6 copolymer anchors along the interface to function as an effective compatibilizer. The addition of SMA resulted in: (1) enhanced miscibility as reflected in the finer morphology, (2) decreased PA6 crystallinity, and (3) improved molecular motion in amorphous PA6 and PPO. The annealing process has induced PA6 crystallization, which leads to further phase separation and more restricted segmental motion. As a result, it improved only the tensile strength but deteriorated both the tensile elongation and impact strength.

The morphology has to take into consideration the correlation between the bulk (tensile strength, tensile elongation, and impact strength) and microscopic properties for PA6/PPO/SMA blend system. The study reveals that the tensile strength depends on the crystallinity, the elongation is influenced by the amorphous domain size, and the Izod impact strength is governed by the amorphous domain size as well as crystallinity. All mechanical properties are found to correlate with $T_{1 \rho}^{H}$ values, which suggest that the mechanical properties can be sensitive to the changes appearing as small as within $100 \AA$. It is expected that the results in present study can be extended to other polymer blends involving semicrystalline components.

Financially support of this research was provided by the National Science Council of Republic of China under contract number NSC-86-2113-M-008-004.

\section{REFERENCES AND NOTES}

1. Bielecki, A.; Burum, D. P.; Rice, D. M.; Karasz, F. E. Macromolecules 1991, 24, 4820.

2. (a) Gao, Z.; Molnar, A.; Morin, F. G.; Eisenberg, A. Macromolecules 1992, 25, 6460; (b) McBrierty, V. T.; Douglass, D. C.; Kwei, T. K. Magn Reson Chem 1994, 32, 853. (c) Campbell, G. C.; VanderHart, D. L. J Magn Reson 1992, 96, 69.

3. Ibbett, R. N. NMR Spectroscopy of Polymers; Blackie Academic and Professional: London, 1993.

4. Mathias, L. J. Solid State NMR of Polymers; Plenum Press: New York, 1988.

5. Zumbulyadis, N. Phys Rev B 1986, 33, 6495.

6. Caravatt, P.; Neuenschwander, P.; Ernst, R. R. Macromolecules 1986, 19, 1895.

7. Vanderhar, D. L.; Barnes, J. D. Macromolecules 1994, 27, 2826.

8. Campbell, J. R.; Hobbs, S. Y.; Shea, T. J.; Watkins, V. H. Polym Eng Sci 1990, 30, 1056.

9. Hobbs, S. Y.; Dekkers, M. E. J.; Watkins, V. H. J Mater Sci 1989, 24, 2025.

10. Nishio, T.; Kuribayashi, H.; Sanada, T. US Patent No. 5237 002, 1993.

11. Laverty, J. J.; Ellis, T.; Ogara, J.; Kim, S. Polym Eng Sci 1996, 36, 347.

12. Ghidoni, D.; Bencini, E.; Nocci, R. J Mater Sci 1996, $31,95$.

13. Lai, Y. C. J Appl Polym Sci 1994, 54, 1289.

14. Kasahara, H.; Fukuda, K.; Suzuki, H. Japanese Patent No. 57-36150, 1982.

15. Chiang, C. R.; Chang, F. C. Polymer 1997, 38, 4807.

16. Weeding, T. L.; Veeman, W. S. Macromolecules 1988, 21, 2028.

17. (a) Costa, D. A.; Silva, E. P.; Oliveira, C. M. F.; Tavares, M. I. B. J Appl Polym Sci 1997, 64, 1635; (b) Grobelny, J. Polymer 1997, 38, 751.

18. Chu, P. P.; Howard, J. J Macromol Chem 1994, 86, 229.

19. Allen, G.; Bevington, J. C. Comprehensive Polymer Science, the Synthesis, Characterization, Reactions, and Applications of Polymers, Vol. II, Polymer Properties; Pergamon: Oxford, 1989. 